\title{
IMPLEMENTASI LINK AGGREGATION CONTROL PROTOCOL UNTUK MENINGKATKAN THROUGHPUT BANDWIDTH PADA UP-LINK LINE
}

\author{
Dwi Haryono $^{1)}$, Herwin' ${ }^{2)}$, Torkis Nasution ${ }^{3)}$ \\ 1, Sistem Informasi, STMIK Amik Riau, Jl. Purwodadi Indah \\ 2.Manajemen Informatika STMIK Amik Riau, Jl. Purwodadi Indah \\ ${ }^{3}$ Teknik Informatika, STMIK Amik Riau, Jl. Purwodadi Indah
}

email:1dwiharyono@stmik-amik-riau.ac.id,2herwin@stmik-amik-riau.ac.id, ${ }^{3}$ torkisnasution@ @stmik-amik-riau.ac.id

\begin{abstract}
The Amik Riau STMIK campus has connected each building using a point to point network with a bandwidth capacity on the available backbone of 85 Mbps, with 368 active users. Based on the network watchdog on the router when maximum usage is obtained, upline streaming data is 8 mbps and downline streaming is 78 mbps. The available bandwidth bandwidth compared to the need is 120 mbps. dividing the work of all data traffic, if there is an increase it will affect the speed of data access so we need a solution so as not to slow down the network. The addition of UpLink Line 2 as a data communication load divider. The Link Aggregation Control Protocol (LACP) method is most appropriate for increasing channel width. The purpose of this study is to identify the channel requirements for the use of local network applications and channel width for outgoing network access to determine the maximum channel width that must be provided. The focus in this research is how to Increase Throughput Bandwidth on Up-Link Line using LACP, followed by how to implement LACP in increasing the channel bandwidth Implementation of LACP to Increase Bandwidth Throughput on UpLink Line. The population in this study are all devices that are listed in the MAC Address server router log table, while the study sample is 20 MAC Address or 60\% of Amik Riau STMIK employees. The theoretical basis used is the TCP / IP protocol, MikroTik, and Data Communication. Testing is done by implementing LACP to Increase Throughput Bandwidth on Up-Link Line. The test results prove the addition of the width of the channel is actually resulting in an increase in throughput generated by 116.3 Mbps / 104.4 Mbps (TX/RX).
\end{abstract}

Key Word: up line, down line, bandwidth, Trougthput, LACP

\begin{abstract}
Abstrak
Kampus STMIK Amik Riau telah menghubungkan setiap gedung menggunakan jaringan point to point dengan kapasitas bandwidth pada backbone tersedia sebesar 85 Mbps, dengan 368 user aktif. Berdasarkan Pengawas jaringan di router pada saat penggunaan maksimal, diperoleh data upline streaming sebesar 8 mbps dan downline streaming sebesar 78 mbps Lebar bandwidth yang tersedia berbanding kebutuhan adalah 120 Mbps.Masalah jaringan saat ini UpLink Line 1 merupakan jalur transmisi standar dari router 1 ke router 2 membagi kerja seluruh lalu lintas data, apabila terjadi peningkatan maka akan berpengaruh terhadap kecepatan akses data sehingga di butuhkan solusi agar tidak memperlambat jaringan. Penambahan jalur UpLink Line 2 sebagai pembagi beban komunikasi data. Metode Link Aggregation Control Protocol (LACP) yang paling tepat untuk meningkatkan lebar kanal. Tujuan penelitian ini adalah mengidentifikasi kebutuhan kanal untuk penggunaan aplikasi jaringan lokal dan lebar kanal untuk akses outgoing jaringan untuk menentukan lebar kanal maksimal yang harus disediakan. Fokus dalam penelitian ini adalah bagaimana Meningkatkan Throughput Bandwidth pada Up-Link Line menggunakan LACP, dilanjutkan dengan bagaimana mengimplementasikan LACP dalam meningkatkan kanal bandwidth Implementasi LACP untuk Meningkatkan Throughput Bandwidth pada Up-Link Line. Populasi dalam penelitian ini adalah seluruh device yang terdaftar di dalam log table MAC Address server router, sedangkan sampel penelitian adalah 20 MAC Address atau 60\% pegawai STMIK Amik Riau. Landasan teori yang digunakan adalah protocol TCP/IP, MikroTik, dan Komunikasi Data. Pengujian dilakukan dengan Implementasi LACP untuk Meningkatkan Throughput Bandwidth pada Up-Link Line. Hasil pengujian membuktikan penambahan lebar kanal sebesdar sehingga terjadi peningkatan throughput yang dihasilkan sebesar 116,3 Mbps/104,4 Mbps (TX/RX).
\end{abstract}

Kata Kunci: Up line, Down Line, Bandwidth, Trougthput, LACP 


\section{PENDAHULUAN}

Organisasi yang sehat, mengalir deras informasi melalui media transmisi yang tersedia dalam upaya menjalankan mekanisme kepemimpin. (Sunarti \& Fitriandini, 2017) Arus informasi tersebut membutuhkan lebar kanal yang berbeda-beda untuk setiap jenis data yang ditransmisikan. Infrastruktur jaringan dalam internal organisasi ditopang oleh teknologi terbaik agar handal, reliable, dan tahan. (Irawati, Hariyani, \& Hadiyoso, 2017)

Jaringan point to point menghubungkan dua perangkat secara langsung digunakan untuk mendukung backbone jaringan.(Duskarnaen \& Nurfalah, 2017) Pada saat ini, STMIK Amik Riau telah menghubungkan setiap gedung menggunakan jaringan point to point dengan lebar kanal yang tersedia adalah $90 \mathrm{MB} / \mathrm{s}$. (Arifin, 2017). Lebar kanal tersebut tidak terpenuhi, hal ini dibuktikan oleh argumentasi berikut:

1. Jaringan internet tersambung ke end point menggunakan router $10 / 100$

2. Jaringan point to point dari Gedung A ke Gedung B menggunakan router 10/100

3. Lebar kanal yang telah tersedia adalah $90 \mathrm{MB} / \mathrm{s}$

4. Bila di gedung A mengakses video sebanyak 10 user dengan kebutuhan $7 \mathrm{MB} / \mathrm{s}$, maka dibutuhkan 70MB.

5. Lebar kanal yang masih tersisa untuk dapat digunakan di Gedung B adalah 20MB/s

6. Bila di Gedung B, ada 3 user mengakses video, atau 10 user mengakses Internet tanpa content video, maka kapasitas terpasang sudah habis terpakai. (Hermansyah, Haryono, \& Efendi, 2018).

Beban pada UpLink Line 1 merupakan kanal atau jalur bandwidth standar sebagai tulang punggung jaringan dan Uplink Line 2 merupakan kanal tambahan yang juga digunakan untuk bandwidth tambahan sebagai solusi pembagian beban kerja jaringan. Masalah jaringan saat ini UpLink Line 1 merupakan jalur transmisi standar dari router 1 ke router 2 yang akan menanggung seluruh lalu lintas data jika dan apabila terjadi peningkatan maka akan berpengaruh terhadap kecepatan akses data sehingga di butuhkan solusi atau tidak memngganggu atau memperlambat kinerja jaringan salah satunya adalah dengan menambah jalur UpLink Line 2 sebagai pembagi beban komunikasi data. (NUGROHO \& FALLAH, 2018)

Secara at list, jaringan point to point telah menggunakan fiber optik, namun tidak didukung oleh perangkat yang memadai. Sehingga, setiap start point tersedia device router kemudian tersambung ke fiber optic via inverter pada endpoint, fiber optic tersambung ke router via converter. Walaupun lebar kanal yang mampu disediakan oleh fiber optic sejumlah $10 \mathrm{~GB} / \mathrm{s}$, namun tidak dapat dioptimalkan, karena perangkat router tidak mendukung. Sementara untuk melakukan penggantian seluruh device, akan membutuhkan biaya mahal. (Tulloh, 2017)

Media transmisi kabel UTP menjadi salah satu solusi yang reliable untuk mengatasi masalah. Setiap kabel UTP memiliki lebar kanal $90 \mathrm{Mbps}$, dalam penelitian ini akan menganalisa penggabungan 3 buah link jaringan menggunakan kabel UTP menjadi satu link backbone, sehingga dapat mengatasi kekurangan lebar kanal terpasang. Teknik ini akan menggunakan LACP, memungkinkan penggabungan beberapa antarmuka seperti ethernet ke dalam satu virtual link, sehingga dapat meningkatkan kapasitas lebar kanal. (Muhammad Zunaidi, 2014)

Penerapan LACP untuk meningkatkan performa jaringan dapat dilakukan di berbagai perangkat seperti router, switch, server, dan firewall. Dalam penelitian ini LACP diterapkan pada perangkat switch. (Sukendar \& Saputro, 2019). Perangkat ini dipilih karena mampu mengkomunikasikan layanan dari banyak client dalam beberapa virtual local area network (VLAN) ke server ataupun sebaliknya. Kondisi switch yang memiliki platform berbeda-beda mengakibatkan perangkat ini dipilih untuk menunjukkan sifat universal dari protokol LACP. Selain itu, ketersediaan interface yang banyak dibandingkan dengan perangkat router, server, dan firewall menjadikan switch mampu membentuk jalur agregasi yang banyak. Sehingga, performa LACP yang signifikan dapat diidentifikasi pada jalur agregasi tersebut. Penelitian tentang LACP dengan menggunakan switch telah dilakukan oleh beberapa peneliti. Simulasi pada jaringan redudansi untuk melihat hasil konfigurasi LACP berupa pencegahan loop dan manajemen bandwidth.. Penelitian Iayer terbatas pada penerapan metode konfigurasi LACP dan pengujian dengan pemutusan jalur agregasi tanpa pembuktian performa throughput. Dalam penelitian ini, LACP dikonfigurasi pada perangkat real switch Catalyst 2960-s dan Nexus $3048 T P$ dalam mode active standby yang kemudian diuji dengan pemutusan jalur dan penetration test untuk mengidentifikasi performa high availability dan high reliability. (Amin, 2014)

\section{METODE PENELITIAN}


1. Rancangan penelitian ini menggunakan metode orientasi dan observasi. Orientasi dilaksanakan sebelum diadakan perbaikan lebar kanal, sedangkan observasi dilaksanakan pada waktu berlangsungnya perbaikan lebar kanal.

2. Langkah-langkah Penelitian, penelitian implementasi LACP dalam jaringan backbone internal, akan dilaksanakan secara sekuensial. Setiap langkah adalah:

a. Planning (rencana), meliputi: mengidentifikasi masalah.

b. Action (Tindakan), meliputi: melaksanakan langkah-langkah sesuai perencanaan; menerapkan protokol LACP; melakukan pengamatan terhadap setiap langkahlangkah kegiatan sesuai rencana.

c. Observation (pengamatan), meliputi: melakukan diskusi dengan penelitian untuk rencana observasi; melakukan pengamatan terhadap penerapan protokol LACP; mencatat setiap kegiatan dan perubahan yang terjadi saat penerapan protokol LACP.

d. Reflection (refleksi), meliputi: menganalisis temuan saat pelaksanaan observasi, menganalisis kelemahan dan keberhasilan peneliti dalam implementasi protokol LACP dan mempertimbangkan langkah selanjutnya.

Pengelolaan data meliputi create, read, update dan delete.

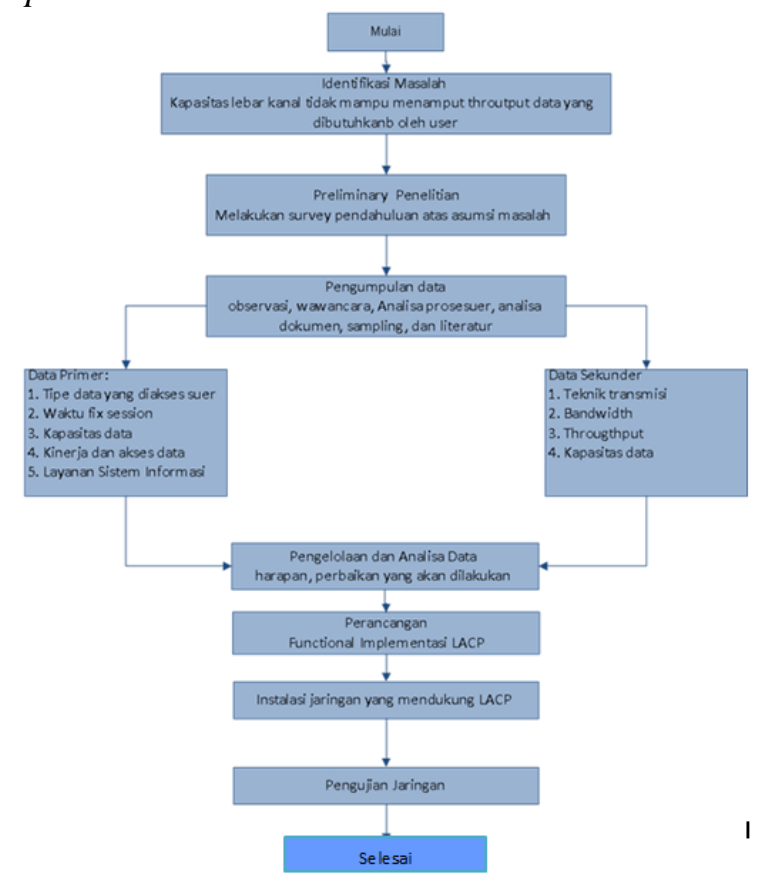

Gambar 1. Metode Penelitian
Arsitektur jaringan komputer saat ini dapat di kategorikan bertopologi mesk pada gambar di bawah ini;

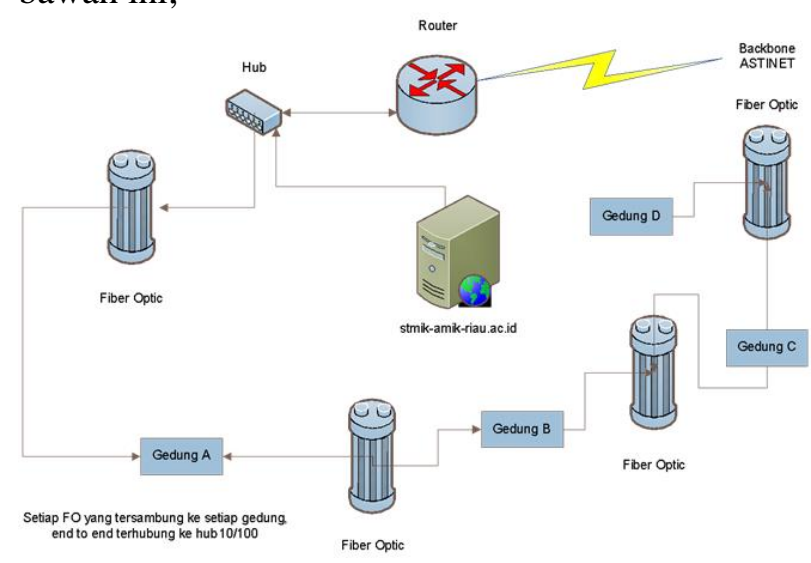

Gambar 2. Blok Diagram Arsitektur Jaringan

\subsection{Topologi yang sedang berjalan}

Topologi router A diteruskan kembali menuju router B untuk di bagikan kepada user, seperti pada gambar berikut ini:

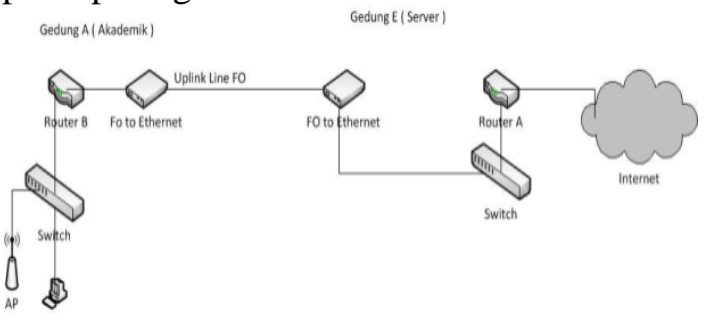

Gambar 3. Topologi yang sedang berjalan

\subsection{Topologi perbaikan}

Topologi perbaikan merupakan pengembangan dari topologi yang sedang berjalan dengan menambahkan uplink line dari router A ke router B yang bekerja untuk meningkatkan kinerja bandwidth, seperti pada gambar berikut ini :

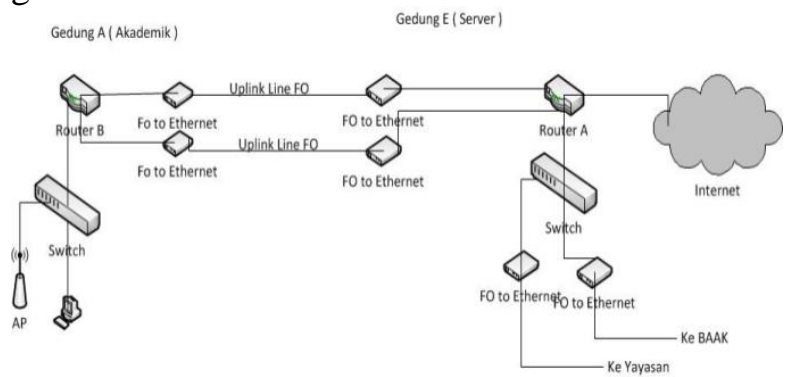

Gambar 4. Topologi perbaikan

\subsection{Bagan Alir Penelitian}

Penerapan LACP kinerja Point A Router dengan Point $\mathrm{B}$ Router terjadi pembagian konsentrasi lalu lintas data dengan menambahkan kanal tambahan sehingga dengan kemampuan router yang ada dapat ditingkatkan

\section{Hasil dan Pembahasan}


atau kinerja router bisa maksimal, dapat dilihat pada gambar;

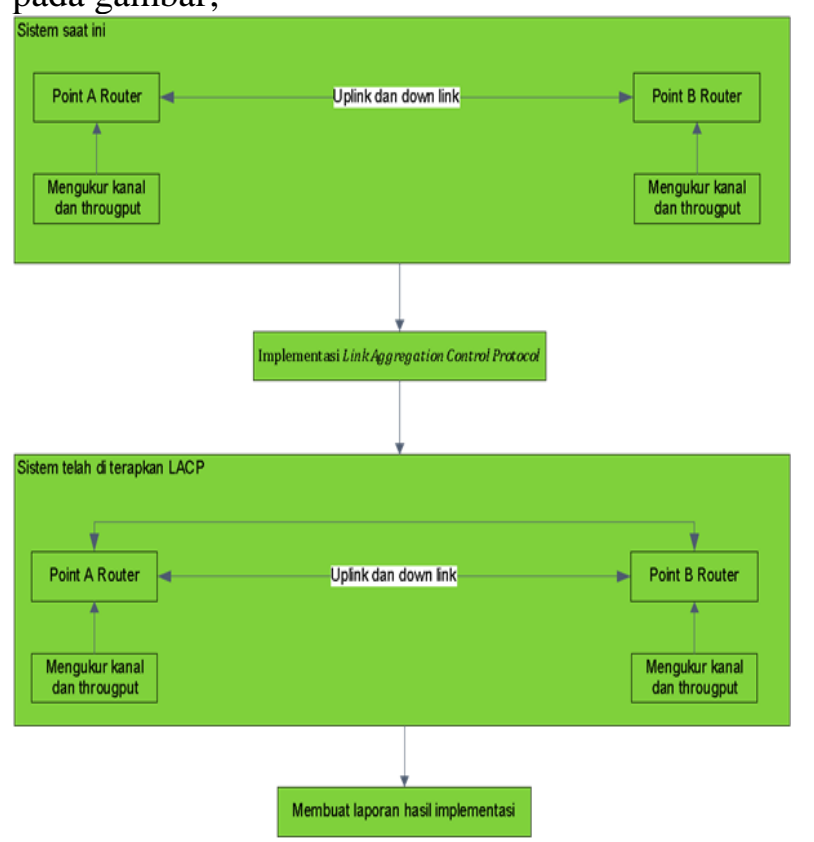

Gambar 5. Bagan Alir Penelitian

\subsection{Indikator Capaian}

1. Transfer rate dapat meningkat $25 \%$ dari throughput sebelum menggunakan LACP, hal ini bisa bertambah dengan kapasitas CPU yang ada pada router.

2. Mengatasi kekurangan bandwidth pada gedung A, sehingga aktivitas oleh pengguna ke server dapat berjalan lancar.

3. Mampu membagi beban sehingga apabila link pada line 1 terputus masih ada line 2 sebagai cadangan koneksi, sehingga akses data ke gedung A masih tetap berjalan walaupun throughput turun $50 \%$.

\subsection{Pengujian pengiriman troughput jaringan sedang berjalan}

Data yang di gunakan bisa di asumsikan menyesuaikan besaran data yang terdapat pada media pengiriman dengan besaran yang telah di tentukan, seperti pada gambar dibawah ini :

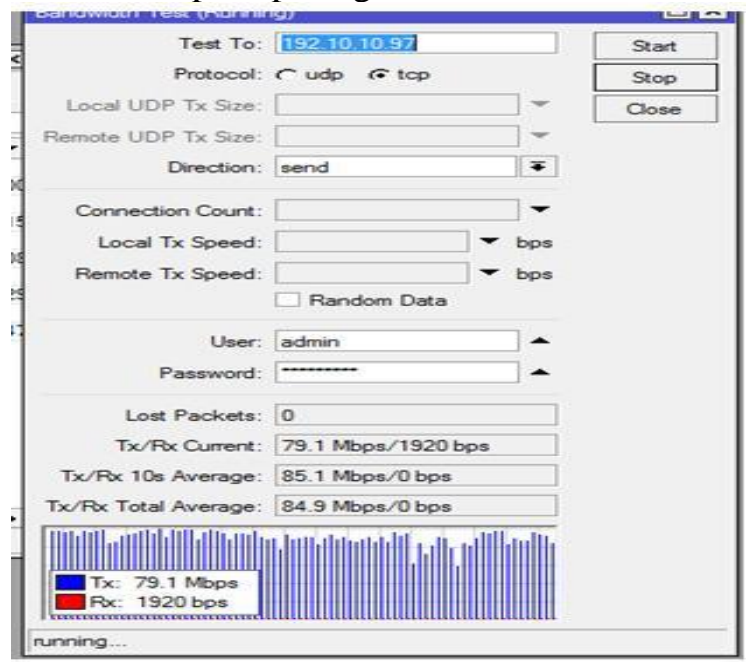

Gambar 6. Troughput Transmited (TX) dari gedung E (Server) ke gedung A (Akademik) perbaikan proses transmit

\subsection{Membandingkan Beban pada UpLink Line 1 dan Uplink Line 2}

Penghitungan dan pembandingan beban jaringan yang sama belum menggambarkan kinerja yang sama dan belum maksimal ethernet diantara port 1 dan 2 terhadap uplink.

Tabel 1. Membandingkan Beban pada UpLink Line 1 dan Uplink Line 2 Troughput Transmited perbaikan proses transmit

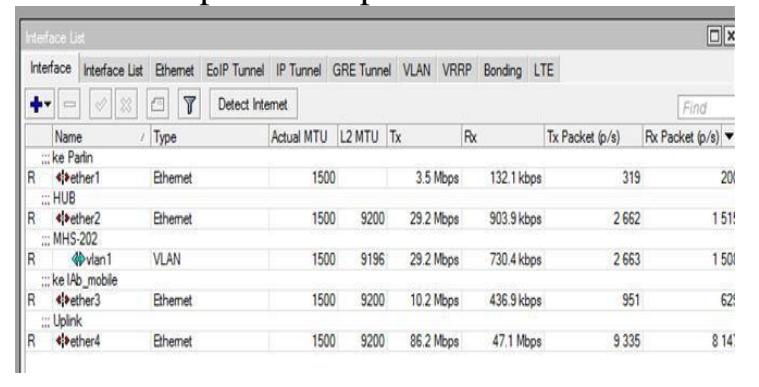

\subsection{Troughput Recieved (RX) dari gedung $\mathrm{E}$} (Server) ke gedung A (Akademik) perbaikan proses transmit

Data yang di gunakan bisa di asumsikan menyesuaikan besaran data yang terdapat pada media pengiriman dengan besaran yang telah di tentukan, seperti pada gambar dibawah ini :

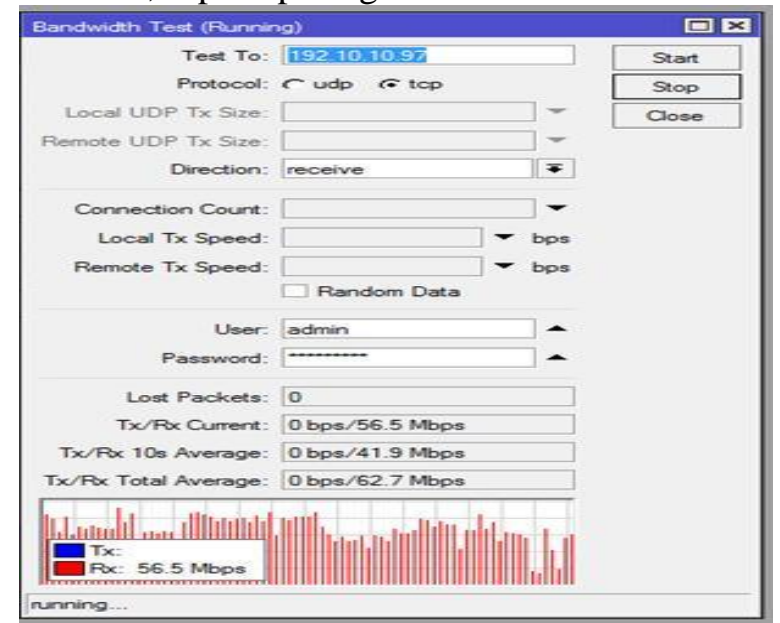

Gambar 7. Troughput Recieved (RX) dari gedung E (Server) ke gedung A (Akademik) pada proses jaringanperbaikan proses transmit

\subsection{Membandingkan Beban pada UpLink Line 1 dan Uplink Line 2 \\ Penghitungan dan pembandingan beban} jaringan yang sama belum menggambarkan kinerja yang sama dan telah maksimal ethernet diantara port 1 dan 2 terhadap uplink.

Tabel 2. Troughput Recieved Membandingkan Beban pada UpLink Line 1 dan Uplink Line 2 


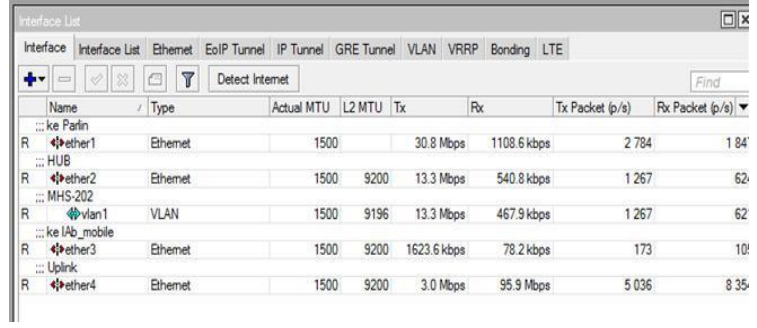

3.10. Pengujian troughput Transmited (TX) dari gedung $\mathbf{E}$ (Server) ke gedung $\mathbf{A}$ (Akademik) perbaikan proses transmit.

Data yang di gunakan bisa di asumsikan menyesuaikan besaran data yang terdapat pada media pengiriman dengan besaran yang telah di tentukan, seperti pada gambar dibawah ini :

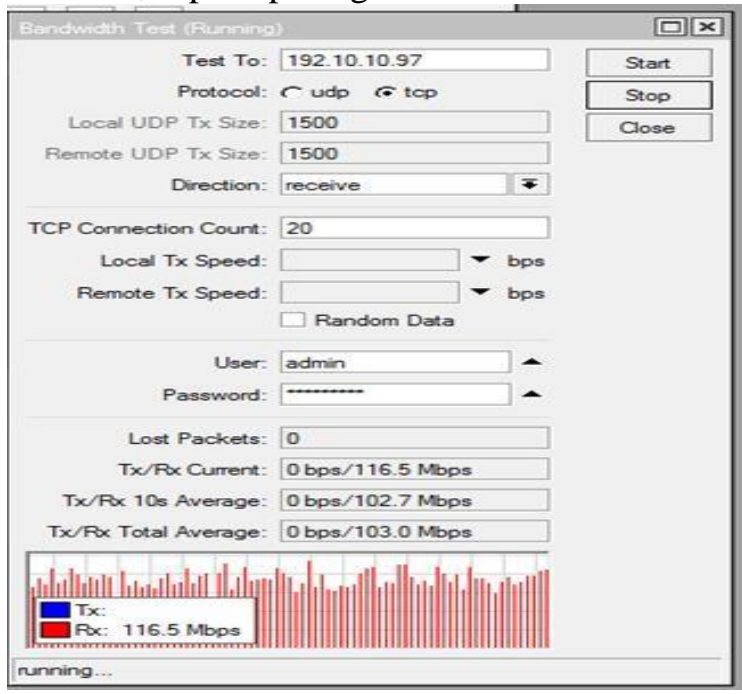

Gambar 8. Troughput Transmited (RX) dari gedung E (Server) ke gedung A (Akademik) perbaikan proses transmit

\subsection{Membandingkan Beban pada UpLink Line 1 dan Uplink Line 2}

Penghitungan dan pembandingan beban jaringan yang sama belum menggambarkan kinerja yang sama dan telah maksimal ethernet diantara port 1 dan 2 terhadap uplink.

Tabel 3. Troughput Recieved Membandingkan Beban pada UpLink Line 1 dan Uplink Line 2

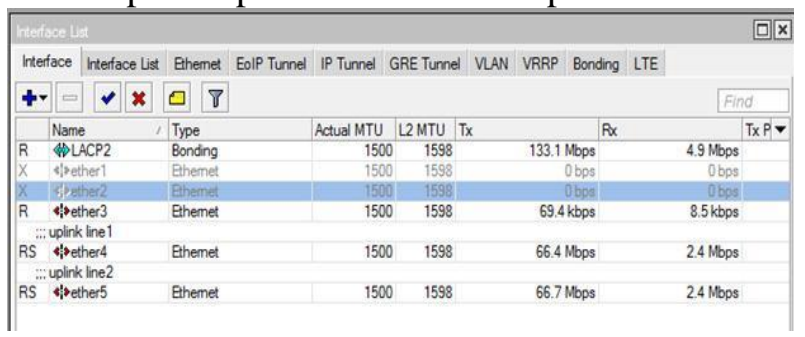

\subsection{Pengujian troughput transmited (RX)} dari gedung A (Akademik) ke gedung $\mathrm{E}$ (Server) perbaikan proses transmit

Data yang di gunakan bisa di asumsikan menyesuaikan besaran data yang terdapat pada media pengiriman dengan besaran yang telah di tentukan, seperti pada gambar dibawah ini :

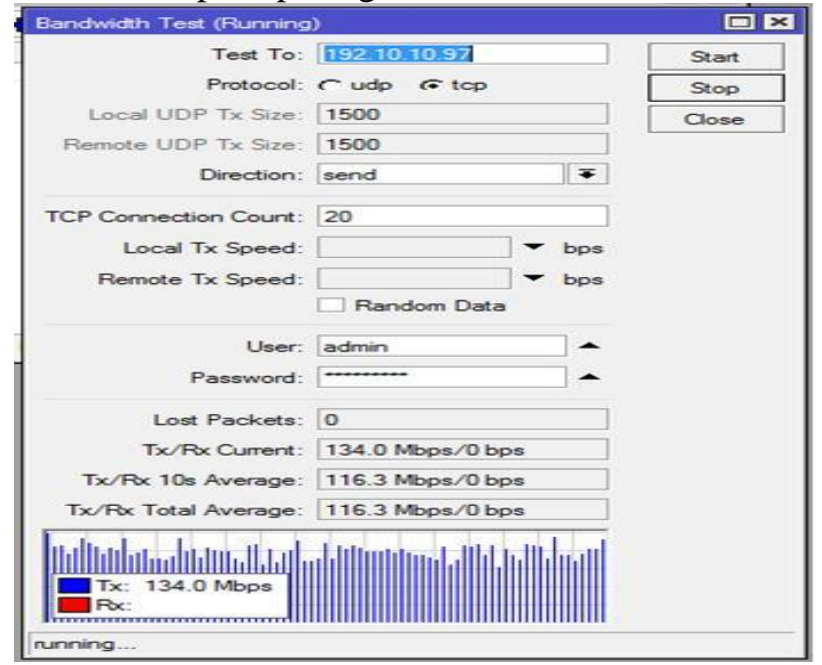

Gambar 9. Pengujian troughput transmited (RX) dari gedung A (Akademik) ke gedung E (Server) perbaikan proses transmit

\section{3,13. Membandingkan Beban pada UpLink Line 1 dan Uplink Line 2 \\ Penghitungan dan pembandingan beban} jaringan yang sama belum menggambarkan kinerja yang sama dan telah maksimal ethernet diantara port 1 dan 2 terhadap uplink.

Tabel 3. Troughput Recieved Membandingkan Beban pada UpLink Line 1 dan Uplink Line 2

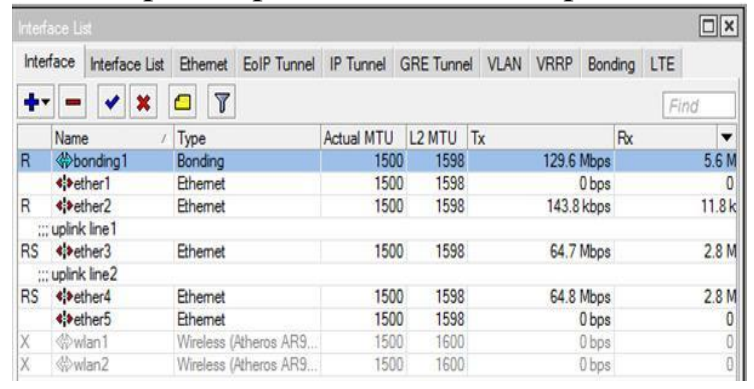

\subsection{Pengujian troughput Transmited (TX)} dari gedung A (Akademik) ke gedung $\mathrm{E}$ (Server) perbaikan proses transmit

Data yang di gunakan bisa di asumsikan menyesuaikan besaran data yang terdapat pada media pengiriman dengan besaran yang telah di tentukan, seperti pada gambar dibawah ini : 


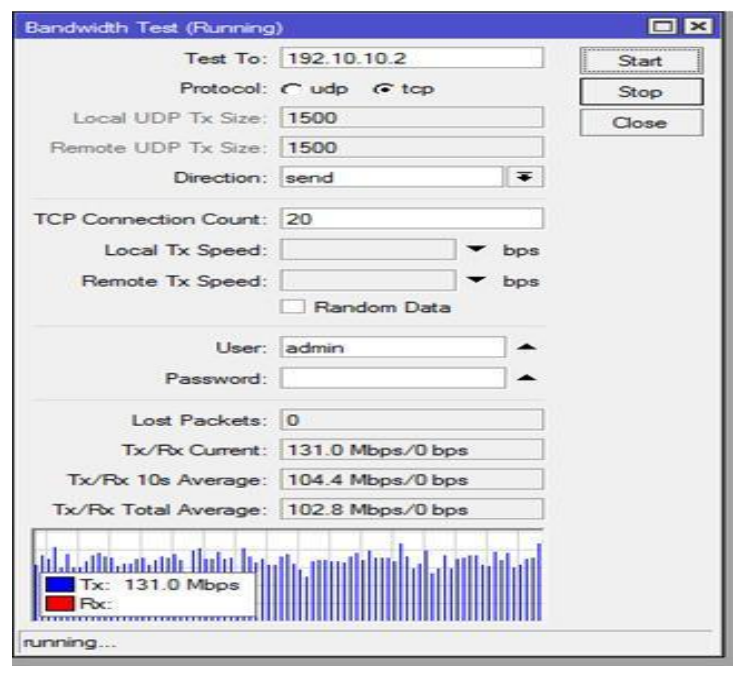

Gambar 10. Pengujian troughput Transmited (TX) dari gedung A (Akademik) ke gedung E (Server) perbaikan proses transmit

\subsection{Membandingkan Beban pada UpLink Line 1 dan Uplink Line 2}

Data yang di gunakan bisa di asumsikan menyesuaikan besaran data yang terdapat pada media pengiriman dengan besaran yang telah di tentukan, seperti pada gambar dibawah ini :

Tabel 4. Troughput Recieved Membandingkan Beban pada UpLink Line 1 dan Uplink Line 2

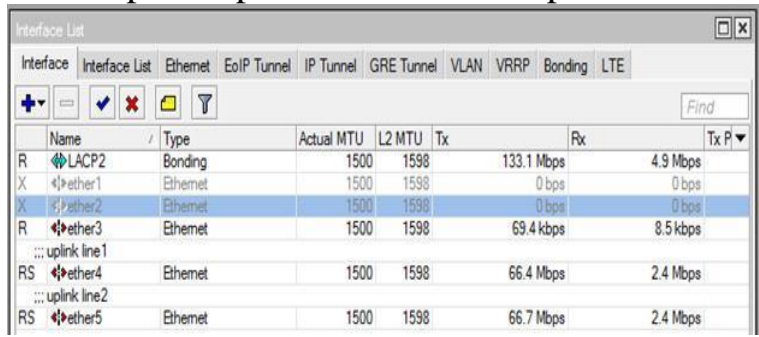

3.16. Pengujian troughput Recieved (RX) dari gedung $\mathrm{E}$ (Server) ke gedung $\mathrm{A}$ (Akademik) perbaikan proses transmit

Data yang di gunakan bisa di asumsikan menyesuaikan besaran data yang terdapat pada media pengiriman dengan besaran yang telah di tentukan, seperti pada gambar dibawah ini :

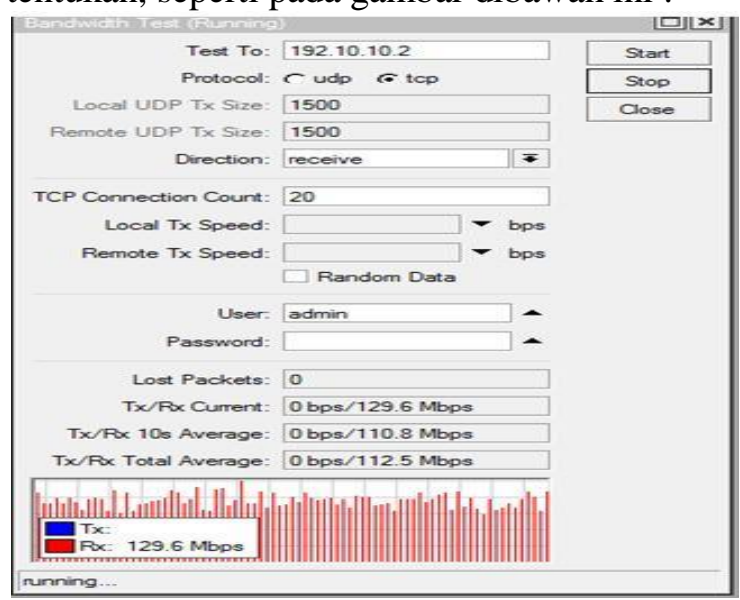

Gambar 11. Pengujian troughput Recieved (RX) dari gedung E (Server) ke gedung A
(Akademik) perbaikan proses transmit

\subsection{Membandingkan Beban pada UpLink Line 1 dan Uplink Line 2}

Data yang di gunakan bisa di asumsikan menyesuaikan besaran data yang terdapat pada media pengiriman dengan besaran yang telah di tentukan, seperti pada gambar dibawah ini :

Tabel 5. Troughput Recieved Membandingkan

Beban pada UpLink Line 1 dan Uplink Line 2

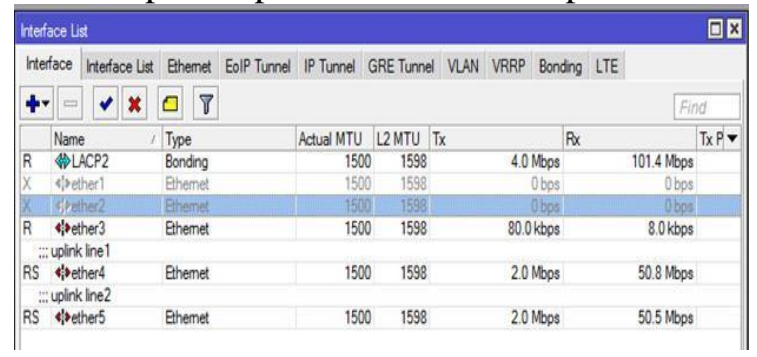

\section{SIMPULAN}

Setelah menyelesaikan penelitian ini dengan membandingkan kedua metode maka dapat menarik kesimpulan sebagai berikut :

1. Penelitian ini dapat meningkatkan Troughtput pada jaringan antar gedung, yang semula pengiriman dan penerimaan data sebesar 85,1 Mbps/41,9 Mbps meningkat menjadi 116,3 Mbps/104,4 Mbps.

2. Jika salah satu uplink line putus maka tidak terjadi redudancy pada jaringan walau kinerja sedikit menurun, hal ini merupakan sistem yang terdapat di dalam ethernet. Diamana apabila diantara Ethernet mengalami gangguan atau kerusakan maka tidak akan mengganggu kinerja Ethernet lainnya.

\section{UCAPAN TERIMAKASIH}

Rangkaian menyelesaikan Penelitian ini peneliti mengucapkan terima kasih kepada STMIK Amik Riau dalam pemberi hibah dan STIKOM Pelita Indonesia yang telah bersedia menerbitkan artikel pada Jurnal JOISIE, sehingga penelitian ini dapat diselesaikan.

\section{DAFTAR PUSTAKA}

Amin, Z. (2014). Simulasi Dan Perancangan Keamanan Autentikasi Jaringan Hirarki Link Aggregation Control Protocol (LACP) Berbasis Router Cisco (STUDI KASUS: STMIK PALCOMTECH). 3(September), 138-144. Retrieved from http://seminar.ilkom.unsri.ac.id/index.php/k ntia/article/view/730 
Arifin, M. A. S. (2017). Analisis Peningkatan Troughput Bandwidth Menggunakan Link Aggregation untuk Jaringan Point to Point. 9(2), 108-115. https://doi.org/10.32767/JTI.V9I2.92

Duskarnaen, M. F., \& Nurfalah, F. (2017). Analisis, Perancangan, Dan Implementasi Jaringan Wireless Point To Point Antara Kampus A Dan Kampus B Universitas Negeri Jakarta. PINTER: Jurnal Pendidikan Teknik Informatika Dan Komputer, 1(2), 134-141. https://doi.org/10.21009/pinter.1.2.6

Hermansyah, Haryono, D., \& Efendi, Y. (2018). Rancang Bangun Manajemen Trafik Routing Jaringan Pada Sistem Informasi Pengelolaan Keuangan Daerah Kabupaten Bengkalis. 2(1), 10-17. https://doi.org/https://doi.org/10.35145/joi sie.v2i1.241

Irawati, L. D., Hariyani, Y. S., \& Hadiyoso, S. (2017). Link Aggregation Control Protocol on Software Defined Network. International Journal of Electrical and Computer Engineering (IJECE), 7(5), 2706 2712.

https://doi.org/http://doi.org/10.11591/ijec e.v7i5.pp2706-2712

Muhammad Zunaidi, B. A. \& S. (2014). Membentuk Jaringan Peer to peer menggunakan kabel firewire ieee-1394 dengan metode bridge. Saintikom, 13(2), 107-120. Retrieved from https://vdocuments.site/issn-1978-6603prpm-menggunakan-kabel-ini-diperlukancara-khusus-atau-yang.html

Nugroho, K., \& FALLAH, M. S. (2018). Implementasi Load Balancing menggunakan Teknologi EtherChannel pada Jaringan LAN. ELKOMIKA, 6(3), 420-435. Retrieved from https://ejurnal.itenas.ac.id/index.php/elko mika/article/view/2054

Sukendar, T., \& Saputro, M. I. (2019). Analisa Jaringan LAN menggunakan Teknologi EtherChannel untuk Meningkatkan Performa Jaringan pada SMU Panca Sakti Jakarta. 5(2), 99-106. Retrieved from http://ejournal.urindo.ac.id/index.php/TI/a rticle/view/636

Sunarti, \& Fitriandini, I. (2017). 1), 2). Aplikasi Sistem Penyidikan Berbasis Client Server Pada Ditreskrimsus Polda Riau, 1(1), 168.

https://doi.org/https://doi.org/10.35145/joi sie.v2i1.241
Tulloh, R. (2017). Analisis Performansi Agregasi Link dengan Lacp pada SDN menggunakan RYU sebagai Controller. Jurnal Nasional Teknik Elektro, 6(3), 10-12. https://doi.org/10.25077/jnte.v6n3.444.2017 